\title{
Triatomíneos: ação ovicida de alguns piretróides
}

\author{
Triatomine: ovicida action of some pyretroids \\ Vera Lúcia Cortiço Corrêa Rodrigues', Antenor do Nascimento Ferraz Filho', \\ Eduardo Olavo da Rocha e Silva' e George Kenge Ishihata'
}

\begin{abstract}
Resumo A ação ovicida dos inseticidas tem sido pouco considerada nas atividades de controle dos transmissores da endemia chagásica. No sentido de comparar o potencial ovicida de três piretróides sintéticos (lambdacialotrina, alphacipermetrina e deltametrina) utilizados no combate aos triatomíneos, os autores realizaram provas em laboratório, cujos resultados, nas condições adotadas, foram favoráveis a lambdacialotrina. As espécies testadas foram Panstrongylus megistus e Triatoma sordida, sendo esta última mais suscetível aos piretróides testados.
\end{abstract}

Palavras-chaves: Inseticida. Piretróides. Triatomíneos. Controle. Ação ovicida.

Abstract The insecticidal action on eggs of triatomine have been little considered in the control activitys of Chagas' disease. With objetive of to compare the potential of three synthetic pyrethroids (deltamethrin, alphacypermethrin and lambdacyhalothrin) on eggs, the authors realized laboratory tests. The pyretroid lambdacialotrin is more efficient. The following species were used in this experiment: Panstrongylus megistus and Triatoma sordida. The specie Triatoma sordida is more susceptible with the pyrethroids utilized.

Key-words: Insecticide. Pyrethroids. Triatomines. Control. Insecticidal action on eggs.

A ação ovicida dos inseticidas sobre os ovos dos triatomíneos tem importância relativa, uma vez que eles são insetos de metamorfose incompleta (Hemimetabólicos) ou seja, são ápteros quando na fase de ninfa, fato que os obriga a buscar o alimento caminhando pelas paredes tratadas.

Embora a Organização Sanitária Panamenricana ${ }^{7}$ afirmasse, em passado recente, a inexistência de ovicidas eficientes em relação aos triatomíneos o interesse pelo assunto advêm da freqüência com que são encontrados ovos, no decurso das atividades de campo, no controle dos transmissores da endemia chagásica. Emmanuel Dias ${ }^{3}$, em 1958, já tinha sugerido que a reinfestação da casa tratada poderia acontecer a partir de ovos oriundos da geração morta, no caso, pelo hexaclorocicloexano (BHC).

Para Mariconi ${ }^{4}$, ovicidas são inseticidas que matam ovos agindo através do córion, interrompendo o desenvolvimento e impedindo a eclosão da ninfa. Vale recordar que ao serem expelidos pela fêmea os ovos apresentam uma coloração branca, tornando-se aos poucos róseos e por fim avermelhados na medida em que se aproxima o momento do nascimento da ninfa do primeiro estádio (Barretto) ${ }^{1}$. O período de incubação varia com a espécie e condições ambientais, notadamente a temperatura. Segundo Sherlock ${ }^{8}$, este período não duraria menos de oito dias em condições de laboratório.

No estudo da ação ovicida dos inseticidas sobre os ovos dos triatomíneos, duas situações bem distintas devem ser levadas em consideração. Na primeira, os ovos já se encontram dispersos sobre a superfície antes do tratamento pelo inseticida e na outra, os ovos somente serão dispersos sobre a superfície após a aplicação do defensivo químico sobre a mesma. Muitos fatores também pesam, tais como: o inseticida e seu tempo de ação, o tipo de superfície tratada, a espécie do triatomíneo, a idade dos ovos as condições ambientais e outros mais. Neste estudo são comparados os resultados da ação ovicida de três piretróides sintéticos, encontrados no comércio, sobre os ovos dos transmissores da doença de Chagas mais presentes nas unidades domiciliares (casas + peridomicílios) do planalto paulista. Foram acompanhadas também as ninfas eclodidas de ovos, dispersos sobre as superfícies tratadas, em diferentes períodos de tempo após a aplicação do piretroide.

\footnotetext{
1. Superintendência de Controle de Endemias (SUCEN), Mogi Guaçu, SP.

Endereço para correspondência: Dra Vera Lúcia Cortiço Corrêa Rodrigues. R. Afonso Pessini 86, Caixa Postal 192, $13840-970$ Mogi Guaçu, SP, Brasil. Tel: 5519 3861-1233.

e-mail: verana@dglnet.com.br

Recebido em 15/5/2001.
} 


\section{MATERIAL E MÉTODOS}

Na realização do trabalho, foram utilizadas placas de Petri, com $11,5 \mathrm{~cm}$ de diâmetro e pouco mais de $1 \mathrm{~cm}$ de altura, que receberam 20 ovos férteis das seguintes espécies: Triatoma infestans, Triatoma sordida, Panstrongylus megistus e Rhodnius neglectus. Devido a problemas na disponibilidade de ovos, no insetário, as últimas provas do trabalho foram realizadas com apenas duas das espécies atualmente mais importantes no Estado de São Paulo, T. sordida e P. megistus.

Na prova I, as placas de Petri, através de sorteio prévio, foram borrifadas pelos respectivos piretróides, com os ovos já dispersos sobre o papel de filtro (tipo Klabin 80) que servia de forro em cada uma delas. Na mesma ocasião, as placas de Petri referentes as outras provas receberam o mesmo tratamento, porém na ausência dos ovos. Nessas, os ovos somente foram dispersos sobre as placas tratadas cerca de 28, 61 e 103 dias após a aplicação dos respectivos piretróides. As placas identificadas com 0 número 1 , foram tratadas com o piretróide $A$; as placas que receberam o número 2 , foram tratadas pelo piretróide $\mathrm{B}$; as placas numeradas com o número 3 , foram tratadas pelo piretróide $\mathrm{C}$ e finalmente, aquelas com que receberam o número 4 (controle), tratadas com água. Em todos os casos, a borrifação foi efetivada com a utilização de um pulverizador Guarany de 8 litros e bico T-8002. Os motivos que levaram a designação dos inseticidas por letras, foram tentar reduzir as expectativas a respeito deste ou daquele inseticida por parte dos que manusearam as placas de Petri. Os ovos permaneceram em todas as placas em observação, no laboratório, por pelo menos 30 dias. Quando da ocorrência da eclosão da ninfa do primeiro estádio, esta permanecia por algumas horas na placa da Petri tratada e se ainda viva, era transferida para outra placa forrada com o mesmo tipo de papel de filtro, este porém não tratado pelo inseticida. Nesta segunda placa de Petri, após 72 horas de permanência com vida, lhe era oferecido o primeiro repasto (pomba). Quando alimentada e aparentemente saudável, era então considerada sobrevivente no experimento, sendo então transferida para um cristalizador próprio. Em resumo:

Prova I. De acordo com sorteio anterior, o piretróide sorteado foi borrifado sobre o papel de filtro que servia de forro a placa de Petri, com os ovos já dispersos sobre a mesma. Presença em cada placa, de 20 ovos férteis das seguintes espécies: T. infestans, T. sordida, $P$. megistus e R. neglectus.

Prova II (28 dias). Aplicação dos piretróides, nas mesmas condições da prova I, porém sem a presença dos ovos nas placas. Ovos férteis, das mesmas espécies e quantidades da prova I, foram dispersos ao acaso sobre as placas tratadas 28 dias após a borrifação.

Prova II (61 dias). Nas placas borrifadas para serem utilizadas na prova II foram dispersos sobre o papel de filtro apenas 20 ovos férteis do T. sordida e igual número do $P$. megistus, pelas razões já expostas.
Prova II (103 dias). Em placas de Petri ainda não utilizadas, devidamente protegidas porém borrifadas na mesma data das anteriores, foram dispersos 103 dias após a borrifação, 10 ovos férteis de $T$. sordida e 10 ovos férteis de $P$. megistus.

Depois da borrifação as placas de Petri utilizadas nas Provas II (28, 61 e 103 dias) foram guardadas no mesmo local onde permaneceram as placas da Prova I, em condições ambientais, com médias de temperaturas máxima de $28^{\circ} \mathrm{C}$ e mínima de $17^{\circ} \mathrm{C}$, e com umidade relativa média de $73 \%$.

Todos os ovos utilizados no trabalho foram recolhidos ao acaso dos cristalizadores existentes no insetário da SUCEN, em Mogi Guaçu. Os ovos se apresentavam em diferentes fases do processo evolutivo ou seja, uns mais próximos e outros mais afastados do momento da eclosão da ninfa. Sua distribuição pelas placas de Petri foi feita também de forma aleatória, sem considerar o estado evolutivo ou o piretroide presente no papel de filtro que servia de forro à placa. Uma eventual suspeita da utilização de ovos inférteis não se justifica, pois as perdas nas placas controle foram de apenas 2,5\%, em oitenta ovos. Essas duas perdas, vale frisar, aconteceram devido a dificuldades ocorridas no momento do desagalamento (eclosão incompleta) e não a infertilidade dos ovos.

Os piretróides utilizados, gentilmente fornecidos pelos respectivos fabricantes, foram os seguintes:

piretróide A: lambdacialotrina (Icon $10 \mathrm{PM}$ ) 30mg i.a. $/ \mathrm{m}^{2}$;

piretróide B: alphacipermetrina (Dominex 200 SC) 50mg i.a. $/ \mathrm{m}^{2}$; i.a. $/ \mathrm{m}^{2}$

piretróide C: deltametrina (K-Othrine SC 50) 25mg

Os dados assim obtidos foram trabalhados, analisados e quando de interesse, sofreram tratamento estatístico (proporção e qui-quadrado).

Antes da apresentação dos resultados vale destacar que os ovos utilizados nas provas, ao final dos trinta dias de observação, se apresentavam na situação de ovos eclodidos ou de ovos não eclodidos. Os eclodidos, por sua vez, se apresentavam como: a) ovos em que ocorreu a abertura do opérculo, mas a ninfa não encontrou condições para abandonar totalmente a casca; b) eclosão bem sucedida, mas a ninfa recémnascida não chegou a realizar o primeiro repasto e c) a ninfa do primeiro estádio realizou com êxito seu primeiro repasto, sobrevivendo à prova.

Como já foi dito anteriormente, um bom ovicida é aquele inseticida que impede a eclosão da ninfa (Mariconi) ${ }^{6}$. Em obediência a este conceito, para efeito do presente trabalho, a ação ovicida do piretróide considerado foi avaliada pelo número de ovos não eclodidos ao final dos 30 dias de observação. 


\section{RESULTADOS}

Prova I. Ovos atingidos diretamente pelo piretróide.

Na Tabela 1 estão sendo apresentados os números totais de ovos não eclodidos e respectivos percentuais, por espécie e por piretróide aplicado. Pela leitura da
Tabela 1 se observa uma maior ação ovicida do piretróide $A$, comparados seus resultados com aqueles obtidos com a aplicação dos outros dois piretroides utilizados (B e $\mathrm{C})$.

\begin{tabular}{|c|c|c|c|c|c|c|c|c|c|c|}
\hline \multirow{2}{*}{$\begin{array}{l}\text { Triatoma e } \\
\text { no de ovos }\end{array}$} & \multicolumn{2}{|c|}{ Piretróide A } & \multicolumn{2}{|c|}{ Piretróide B } & \multicolumn{2}{|c|}{ Piretróide C } & \multicolumn{2}{|c|}{$\begin{array}{c}\text { Controle } \\
\text { (água) }\end{array}$} & \multicolumn{2}{|c|}{$\begin{array}{c}\text { Total geral } \\
\text { (s/ o controle) }\end{array}$} \\
\hline & $\mathrm{n}^{\circ}$ & $\%$ & $\mathrm{n}^{\circ}$ & $\%$ & $\mathrm{n}^{\circ}$ & $\%$ & $\mathrm{n}^{\circ}$ & $\%$ & $\mathrm{n}^{\circ}$ & $\%$ \\
\hline T. infestans (20) & 19 & 95,0 & 13 & 65,0 & 12 & 60,0 & - & - & 44 & 73,3 \\
\hline T. sordida (20) & 20 & 100,0 & 12 & 60,0 & 11 & 55,0 & 1 & - & 43 & 71,6 \\
\hline P. megistus (20) & 18 & 90,0 & 11 & 55,0 & 10 & 50,0 & - & - & 39 & 65,0 \\
\hline R. neglectus (20) & 18 & 90,0 & 4 & 20,0 & 3 & 15,0 & - & - & 25 & 41,6 \\
\hline Total & 75 & 93,7 & 40 & 50,0 & 36 & 45,0 & 1 & 1,25 & 151 & 62,9 \\
\hline
\end{tabular}

SUCEN/Mogi Guaçu.

O tratamento desses resultados (Tabelas 2 e 3) pelo teste de hipóteses com um grau de liberdade, sugere que a hipótese de igualdade da ação do piretróide $A$ em relação ao B ou C, é altamente improvável. A validade da prova é sustentada pelo número de ovos não eclodidos observados no Controle (4).

Tabela 2 - Teste de hipótese com 1 grau de liberdade entre os piretróides A e B, 1999.

\begin{tabular}{|c|c|c|c|c|}
\hline \multirow[b]{2}{*}{ Piretróide } & \multicolumn{3}{|c|}{ Ovos } & \multirow[b]{2}{*}{ Total } \\
\hline & \multicolumn{2}{|c|}{ não eclodidos } & eclodidos & \\
\hline A & 75 & 93,7 & 5 & 80 \\
\hline B & 40 & 50,0 & 40 & 80 \\
\hline Total & 115 & 71,8 & 45 & 160 \\
\hline
\end{tabular}

(teste do qui-quadrado $p=2,653 \times 10 E-6$ )

SUCEN/Mogi Guaçu.

Prova II ${ }_{28}$. Ovos dispersos sobre placas de Petri, cerca de vinte e oito dias após o tratamento pelo piretróide.

$\mathrm{Na}$ Tabela 4, além do total de ovos não eclodidos, por espécie e por piretroide, a tabela mostra a situação final a que chegaram as ninfas oriundas dos ovos eclodidos no decorrer da prova. Pela leitura, constatase uma redução geral da ação ovicida, lembrando que não ocorreu aplicação direta do piretroide sobre os ovos.

Pela primeira vez, no experimento, algumas ninfas sobreviveram à prova, fato este ocorrido na presença do piretróide $B$. No caso, foram duas $(11,7 \%) T$. infestans, das 17 ninfas que chegaram ao desagalamento e duas (12,5\%) P. megistus, das 16 que nasceram.

Prova $\mathrm{II}_{61}$. Ovos dispersos sobre placas de Petri, 61 dias após o tratamento pelo piretróide.

Os resultados alcançados foram bem menos expressivos que os anteriores, em que pese terem sido realizadas apenas provas com ovos de $T$. sordida e $P$. megistus, pelas razões já expostas. Nos três casos

Com base nos dados apresentados na Tabela 1, foram montadas as Tabelas 2 e 3 .

Nesta prova, nenhuma das ninfas que eclodiram chegaram a realizar o primeiro repasto, morrendo todas em poucas horas independentemente do piretroide aplicado sobre o papel de filtro que servia de forro a placa.

Tabela 3 - Teste de hipótese com 1 grau de liberdade entre os piretróides $A$ e C, 1999.

\begin{tabular}{|c|c|c|c|c|}
\hline \multirow[b]{2}{*}{ Piretróide } & \multicolumn{3}{|c|}{ Ovos } & \multirow[b]{2}{*}{ Total } \\
\hline & \multicolumn{2}{|c|}{ não eclodidos } & eclodidos & \\
\hline $\bar{A}$ & 75 & 93,7 & 5 & 80 \\
\hline C & 36 & 45,0 & 44 & 80 \\
\hline Total & 111 & 69,3 & 49 & 160 \\
\hline
\end{tabular}

(teste do qui-quadrado $p=9,7086 \times 10 E-7$ )

SUCEN/Mogi Guaçu.

(piretróides A, B e C), a maioria dos ovos chegou ao desalagamento, porém todas as ninfas do $T$. sordida morreram antes da realização do primeiro repasto. Quanto ao $P$. megistus, aproximadamente, $26 \%$ delas sobreviveram em cada placa ( Tabela 5).

Prova $\mathrm{II}_{103}$. Ovos dispersos sobre as placas de Petri, 103 dias após o tratamento pelo piretróide. Prova realizada com apenas 10 ovos de $T$. sordida e 10 ovos de P. megistus, dispersos sobre placas de Petri até então não utilizadas e guardadas devidamente protegidas. Todos os ovos de P. megistus deram nascimento as ninfas e em todas as placas, mais de $50 \%$ sobreviveram à prova. No caso de o $T$. sordida, alguns ovos não eclodiram e mais de $40 \%$ das ninfas eclodidas não chegaram a realizar o primeiro repasto (Tabela 6 ).

A Tabela 7 apresenta a evolução das quantidades e dos percentuais e ovos não eclodidos de $T$. sordidae $P$. megistus, no decorrer do desenvolvimento do trabalho. As demais espécies não foram consideradas.

\section{DISCUSSÃO}

Em 1958, Dias ${ }^{3}$ já recomendava a repetição do expurgo domiciliário, com BHC, um a dois meses após o primeiro tratamento devido a breve ação residual e falta de toxidez para ovos de triatomíneos do inseticida. 
Tabela 4 - Situação dos ovos dispersos sobre as placas de Petri, 28 dias após tratamento por piretróide, 1994.

\begin{tabular}{|c|c|c|c|c|c|c|}
\hline \multirow[b]{2}{*}{ Triatomíneo } & \multirow[b]{2}{*}{$\begin{array}{c}\text { Piretróide } \\
\text { aplicado na placa }\end{array}$} & \multirow[b]{2}{*}{$\begin{array}{l}\text { No de ovos } \\
\text { não eclodidos }\end{array}$} & \multicolumn{3}{|c|}{ Ovos eclodidos $\left(\mathrm{n}^{\circ}\right)$} & \multirow[b]{2}{*}{$\begin{array}{l}\text { Total de ovos } \\
\text { observados }\end{array}$} \\
\hline & & & $\begin{array}{c}\text { eclosão } \\
\text { não completa }\end{array}$ & $\begin{array}{c}\text { ninfa não } \\
\text { chegou ao } 1^{\circ} \text { repasso }\end{array}$ & $\begin{array}{c}\text { ninfa } \\
\text { sobreviveu a prova }\end{array}$ & \\
\hline \multicolumn{7}{|l|}{ T. infestans } \\
\hline & A & 13 & 1 & 6 & - & 20 \\
\hline & B & 3 & - & 15 & 2 & 20 \\
\hline & C & 5 & - & 15 & - & 20 \\
\hline & D (controle) & - & - & - & 20 & 20 \\
\hline \multicolumn{7}{|l|}{ T. sordida } \\
\hline & A & 15 & - & 05 & - & 20 \\
\hline & B & 5 & 1 & 14 & - & 20 \\
\hline & C & 8 & - & 12 & - & 20 \\
\hline & D & - & - & - & 20 & 20 \\
\hline \multicolumn{7}{|l|}{ P. megistus } \\
\hline & A & 11 & - & 9 & - & 20 \\
\hline & B & 4 & - & 14 & 2 & 20 \\
\hline & C & 7 & 2 & 11 & - & 20 \\
\hline & D & - & - & - & 20 & 20 \\
\hline \multicolumn{7}{|l|}{ R. neglectus } \\
\hline & A & 6 & 2 & 12 & - & 20 \\
\hline & B & 3 & 2 & 15 & - & 20 \\
\hline & C & 3 & - & 17 & - & 20 \\
\hline & D & - & - & - & 20 & 20 \\
\hline
\end{tabular}

SUCEN/Mogi Guaçu

Tabela 5 - Situação dos ovos dispersos sobre as placas de Petri, 61 dias após tratamento por piretróide, 1994.

\begin{tabular}{|c|c|c|c|c|c|c|}
\hline \multirow[b]{2}{*}{ Triatomíneo } & \multirow[b]{2}{*}{$\begin{array}{c}\text { Piretróide } \\
\text { aplicado na placa }\end{array}$} & \multirow[b]{2}{*}{$\begin{array}{l}\text { No de ovos } \\
\text { não eclodidos }\end{array}$} & \multicolumn{3}{|c|}{ Ovos eclodidos $\left(\mathrm{n}^{\circ}\right)$} & \multirow[b]{2}{*}{$\begin{array}{c}\text { Total de ovos } \\
\text { observados }\end{array}$} \\
\hline & & & $\begin{array}{c}\text { eclosão } \\
\text { não completa }\end{array}$ & $\begin{array}{c}\text { ninfa não } \\
\text { chegou ao } 1^{\circ} \text { repasso }\end{array}$ & $\begin{array}{c}\text { ninfa } \\
\text { sobreviveu a prova }\end{array}$ & \\
\hline \multicolumn{7}{|l|}{ T. sordida } \\
\hline & A & 3 & - & 17 & - & 20 \\
\hline & B & 2 & - & 18 & - & 20 \\
\hline & C & 6 & - & 14 & - & 20 \\
\hline & D (controle) & - & - & - & 20 & 20 \\
\hline \multicolumn{7}{|l|}{ P. megistus } \\
\hline & A & 1 & - & 14 & 5 & 20 \\
\hline & B & 1 & - & 13 & 6 & 20 \\
\hline & C & 2 & - & 13 & 5 & 20 \\
\hline & D & 1 & - & - & 19 & 20 \\
\hline
\end{tabular}

SUCEN/Mogi Guaçu

Tabela 6 - Situação dos ovos dispersos sobre as placas de Petri, 103 dias após tratamento por piretróide. 1994.

\begin{tabular}{|c|c|c|c|c|c|c|}
\hline \multirow[b]{2}{*}{ Triatomíneo } & \multirow[b]{2}{*}{$\begin{array}{c}\text { Piretróide } \\
\text { aplicado na placa }\end{array}$} & \multirow[b]{2}{*}{$\begin{array}{l}\text { No de ovos } \\
\text { não eclodidos }\end{array}$} & \multicolumn{3}{|c|}{ Ovos eclodidos $\left(\mathrm{n}^{\circ}\right)$} & \multirow[b]{2}{*}{$\begin{array}{c}\text { Total de ovos } \\
\text { observados }\end{array}$} \\
\hline & & & $\begin{array}{c}\text { eclosão } \\
\text { não completa }\end{array}$ & $\begin{array}{c}\text { ninfa não } \\
\text { chegou ao } 1^{\circ} \text { repasso }\end{array}$ & $\begin{array}{c}\text { ninfa } \\
\text { sobreviveu a prova }\end{array}$ & \\
\hline \multicolumn{7}{|l|}{ T. sordida } \\
\hline & $A$ & 1 & - & 8 & 1 & 10 \\
\hline & B & 2 & - & 4 & 4 & 10 \\
\hline & $\mathrm{C}$ & 1 & - & 7 & 2 & 10 \\
\hline & $\mathrm{D}$ (controle) & - & - & - & 10 & 10 \\
\hline \multicolumn{7}{|l|}{ P. megistus } \\
\hline & $A$ & - & - & 5 & 5 & 10 \\
\hline & $\mathrm{B}$ & - & - & 2 & 8 & 10 \\
\hline & $\mathrm{C}$ & - & - & 4 & 6 & 10 \\
\hline & $\mathrm{D}$ & - & - & - & 10 & 10 \\
\hline
\end{tabular}

SUCEN/Mogi Guaçu 
Tabela 7 - Número e percentuais de ovos não eclodidos do T. sordida e P. megistus nas quatro provas realizadas, 1994.

\begin{tabular}{|c|c|c|c|c|c|c|c|c|c|c|c|c|}
\hline \multirow{3}{*}{ Provas } & \multicolumn{6}{|c|}{$\begin{array}{c}\text { Triatoma sordida } \\
\text { piretróides }\end{array}$} & \multicolumn{6}{|c|}{$\begin{array}{c}\text { Panstrongylus Megistus } \\
\text { piretróides }\end{array}$} \\
\hline & \multicolumn{2}{|c|}{ A } & \multicolumn{2}{|c|}{$B$} & \multicolumn{2}{|c|}{$\mathrm{C}$} & \multicolumn{2}{|c|}{$A$} & \multicolumn{2}{|c|}{$B$} & \multicolumn{2}{|c|}{$\mathrm{C}$} \\
\hline & $\mathrm{n}^{\circ}$ & $\%$ & $\mathrm{n}^{\circ}$ & $\%$ & $\mathrm{n}^{\circ}$ & $\%$ & $\mathrm{n}^{\circ}$ & $\%$ & $\mathrm{n}^{\circ}$ & $\%$ & $\mathrm{n}^{\circ}$ & $\%$ \\
\hline Prova I & 20 & 100 & 12 & 60 & 11 & 55 & 18 & 90 & 11 & 55 & 10 & 50 \\
\hline Prova $\mathrm{II}_{28}$ & 15 & 75 & 5 & 25 & 8 & 40 & 11 & 55 & 4 & 20 & 7 & 35 \\
\hline Prova II ${ }_{61}$ & 3 & 15 & 2 & 10 & 6 & 30 & 1 & 5 & 1 & 5 & 2 & 10 \\
\hline Prova $\mathrm{II}_{103}$ & 1 & 10 & 2 & 20 & 1 & 10 & - & - & - & - & - & - \\
\hline
\end{tabular}

Prova realizada com 10 ovos de cada espécie. Nas demais, 20 ovos por espécie.

SUCEN/Mogi Guaçu

Em condições de laboratório, Corrêa \& Schiavi² também constataram a mesma falta de ação desse clorogenado sobre ovos de T. infestans. Dias ${ }^{4}$ empregando ainda o $\mathrm{BHC}$ sobre ninfas recém-eclodidas e ovos observou que as ninfas de $T$. infestans e de $P$. megistus se mostraram suscetíveis ao inseticida. Quanto aos ovos, relatou que até 30 dias após a sua aplicação o BHC conseguia interromper a evolução, embora destacasse a necessidade de novos experimentos.

As citações acima apresentadas, acontecidas ainda na época da utilização do BHC como principal arma de combate aos triatomíneos em nosso meio, valem não apenas pelo nome de seus autores mas também por mostrar quão antigo é o interesse dos pesquisadores brasileiros pelo assunto e de sua importância para as atividades de controle da endemia chagásica. Apesar do atual avanço do país nessa área, particularmente na ação contra a principal espécie transmissora, $T$. infestans, as incertezas a respeito da ação ovicida persistem agora em relação aos piretróides sintéticos. Sendo assim, parecem pois oportunas as observações, aqui relatadas, cujas considerações finais são:

A ação de interromper o desenvolvimento da ninfa ainda no interior do ovo foi visivelmente mais efetiva quando da aplicação direta do inseticida sobre o ovo (exocorion), não importando qual o piretróide testado (Prova I). Esta constatação sugere ser o contato direto a melhor via de ação no experimento.

A realização do primeiro repasto pela ninfa recémeclodida foi considerada, no experimento, como prova de sobrevida e final do teste. Esse fato começou a ocorrer a partir da segunda prova (Prova II), quando já não ocorreu a aplicação direta do piretróide sobre os ovos (2 ninfas de T. infestans e 2 de P. megistus).

No experimento, T. sordidamostrou ser a espécie mais suscetível à ação dos piretróides utilizados.

As outras espécies ( $T$. infestans e $R$. neglectus) não foram consideradas por falta de ovos em número suficiente, no insetário, quando da realização das últimas provas.

Assim sendo, nas condições relatadas, onde temperatura e umidade relativa foram as ambientais, o piretroide sintético lambdacialotrina 10PM; 30mg i.a. $/ \mathrm{m}^{2}$, mostrou possuir ação estatisticamente significante sobre os ovos de $P$. megistus e de T. sordida que a dos dois outros piretróides também utilizados no experimento.

Vale lembrar que a utilização da lambdacialotrina como ovicida já havia sido assinalada ${ }^{5}$, embora de maneira genérica.

\section{AGRADECIMENTOS}

Agradecemos as firmas Aventis Crop Science, Syngenta Ltda e FMC Química do Brasil Ltda pela colaboração e apoio. Aos funcionários Vera Lúcia Braga, Pedro Ribeiro da Silva e Antonio Domingues pelo suporte técnico.

\section{REFERÊNCIAS BIBLIOGRÁFICAS}

1. Barretto MP. Transmissores do Trypanosoma cruzi: os triatomíneos. In: Cançado JR (ed) Doença de Chagas Belo Horizonte p. 189-224, 1968.

2. Corrêa RR, Schiavi A. Resistência aos inseticidas do Triatoma infestans em suas diversas fases evolutivas. Folia Clinica et Biologica 22: 57-64, 1954.

3. Dias E. Epidemiologia e profilaxia da doença de Chagas Revista Goiana de Medicina 4: 303-317, 1958.

4. Dias JCP. Suscetibilidade de larvas e ovos de triatomíneos à ação do BHC. Revista Brasileira de Malariologia e Doenças Tropicais 17: 37-47, 1965.
5. International Program of Chemical Safety. Health and Safety Guide no 38 World Health Organization, Geneve, 1980.

6. Mariconi FAM. Inseticidas e seu emprego no combate as pragas. vol 1, 4⿳亠丷厂 edição, Livraria Nobel, São Paulo, 1980.

7. Organizacion Panamericana de la Salud. Informe de um grupo de estudio sobre la enfermedad de Chagas. Publicación Científica, $\mathrm{n}^{\circ}$ 195, Washington DC, 1970.

8. Scherlock IA . Vetores In: Brener Z, Andrade Z (eds) Trypanosoma cruzi e doença de Chagas Guanabara Koogan, $1^{a}$ edição, Rio de Janeiro p. 42-88, 1979. 